\title{
COMMENT
}

\section{American Pediatric Society 2019 Presidential Address: striving to be a lasting blessing to the community}

\author{
Bruce D. Gelb ${ }^{1}$ \\ Pediatric Research (2019) 86:428-431; https://doi.org/10.1038/s41390-019-0470-0
}

"Progress and success, in order to be complete and unmistakable, require centralization of means and co-operation of men."1 Thus Abraham Jacobi began the first Presidential Address to the American Pediatric Society (APS) in 1889. This year is the 130th anniversary of that first APS scientific meeting, a two-day affair held in Washington, DC on the first day and then here in Baltimore on the second. ${ }^{2}$ Sadly, Jacobi was correct in his word choice-our founders' elite organization comprised only men. In creating the APS, they were dealing with existential questions about children's health and Pediatrics as a specialty. In their time, infant mortality exceeded the astounding rate of $10 \%,{ }^{3}$ attributable not just to devastating infectious diseases, both endemic and epidemic, but also to dismal living conditions; child health care that was haphazard at best; and the fact that pediatrics barely existed as a discernable discipline. The APS's constitution had been adopted the year before, in 1888, and, as stated in Article I of that foundational document, the object of the APS was "the advancement of Physiology, Pathology and Therapeutics of Infancy and Childhood." ${ }^{4}$ President Jacobi in his remarks, starting with the quote with which I began, laid out the arguments for the need for scientific-minded physicians devoted to children's health to band together as the American Pediatric Society and advance Pediatrics as a discipline, making the argument, which still resonates today, that children are not merely small adults.

With infant mortality now below $1 \%$ in the United States, albeit nearly double what it is in many of our peer nations, ${ }^{5}$ and Departments of Pediatrics established as de rigueur at all medical schools, the mission of the APS today must address a rather different set of issues relevant to children's health and to our discipline. In recent years, our Society has been guided by the strategic plan of 2012, which was intended to be a 5-year project. While unquestionably successful-for instance, the APS Day at PAS, which we are enjoying today, was an innovation initiated from that plan-, it certainly feels as if much has changed in the world since 2012, suggesting the need to revisit our societal priorities. While some issues such as racism and sexism still very much demand our attention, other challenges such as climate disruption have come to the fore as have some exciting new opportunities such as pediatric precision medicine, and of course, the nature of our national conversation demands more of us as leaders in child health. To that end, the APS undertook strategic planning intensely over the past 24 months. Your Council received thoughtful input from many of the Society's members, in writing, through an exercise at our Networking Luncheon at the 2017 PAS meeting, and through one-on-one interviews. The Council then distilled that feedback down into a framework, which, hopefully, will provide our Society with a compelling roadmap for the coming years. Many in this room have participated in strategic planning exercises for their own institutions or other organizations. We all know that this is difficult work-cases are put forward for a range of attractive options that, tested against the real world of limited resources, time, and effort, must be pruned back iteratively to achieve a focused, yet aspirational plan. I want to very publicly thank the current APS Council members, our APS Association Director Jaimee Chumley, and our APS-SPR Executive Director Eileen Fenton for undertaking the strategic planning this year with such passion and collegiality. I also want to acknowledge the invaluable guidance we received from Merrick Hoben and Tushar Kansal of the Consensus Building Institute. Having been in the room where it happened, I can report that we managed to have fun while working on this mission-critical endeavor for the APS.

The strategic plan has already been formally announced in messaging to the APS membership, ${ }^{6}$ so this morning's plenary cannot be mistaken for a reveal party. Rather, I would like to speak about its three components-career support, advocacy, and thought leadership-providing my own take on each to address the question: How are they relevant to the pressing issues of our day?

Let me begin with career support-our initiative to enable academic pediatric leaders to maximize their professional aspirations. While Pediatrics is established as a discipline and the APS's members, most notably our remarkable Howland and Siegel awardees, provide a resounding affirmative to the question of whether productive academic careers are possible today, there are some significant concerns about our future. We have worked hard to become more inclusive and diverse-surely the 43 white men who founded our society would be amazed. Past Presidents Bruder Stapleton, Barbara Stoll, Donna Ferriero, and, last year, Elena Fuentes-Afflick have poignantly drawn our attention to the progress we have made as a Society, but more importantly, the work we still need to do. ${ }^{7-10}$ Our Committee on Diversity and Inclusion has been a critical focus for making us better, and their ongoing efforts will continue to help us strive forward in that mission.

Still, as I look back over the 35 years since I decided as a fourth year medical student to enter Pediatrics, the most striking demographic change in our specialty is that we have changed from a field that was dominated by men as trainees to one that is predominantly attracting women. Given that fact, which I view as descriptive and ethically neutral, we must find ways to support the needs of young women as they embark on academic pediatric

\footnotetext{
${ }^{1}$ Departments of Pediatrics and Genetics \& Genomic Sciences, Mindich Child Health and Development Institute, Icahn School of Medicine, New York, NY, USA
} Correspondence: Bruce D. Gelb (bruce.gelb@mssm.edu)

Received: 3 June 2019 Accepted: 11 June 2019

Published online: 19 June 2019 
careers or will face a very constricted outlook for our field in the future. To provide one example, there are abundant data showing how leaky the pipeline is for female physician-scientists-the gap from NIH K to R award funding is demonstrably far more daunting for female junior faculty. ${ }^{11}$ This is attributable to myriad factorsdisproportionate childcare burden, lifestyle choices, as well as insufficiently supportive and often inflexible academic structures to cite just a few. We have learned about unconscious bias-recall the studies showing how grant and fellowship applications fare less well when coming from women, and that is true even when the graders are female academics. ${ }^{12,13}$ As this past year has painfully emphasized through the \#MeToo movement, women too often face challenges, if not outright assaults, in the workplace. While we may believe that pediatricians are, on average, nicer than other physicians, and that doctors are generally humanistic individuals, our field is not immune to the ills of society.

Increasingly, our incoming academic pediatricians reflect the diversity of America, which itself has become far more diverse over time. Still, as one looks around this room this morning, the gap between our aspirations and our reality is apparent. After all, it took the APS $>60$ years to accept its first African-American as a member and 130 years until we had our first Latinx President. We have never had a President who was African-American or of Far Eastern ancestry. While Pediatrics needs to work with the rest of medical academia to address the ongoing disparities-we cannot do that alone-we can look at our structures and our processes, many founded at a time of exclusive white privilege, to ask how we can do better in our house.

One goal of our Career Support initiative is to assure that we are helping young academic pediatricians, no matter who they are, enjoy productive careers, supporting them at crucial junctures. In particular, we have identified mentoring gaps for late junior academic pediatricians such as when they are poised to assume their first leadership positions.

Here, I can relate my own experience. As I was making my way as a physician-scientist, having achieved independent research funding and made a few solid genetic discoveries, the opportunities to look at pediatric cardiology division chief positions started flowing in with regularity. My wife will recall vividly me forwarding emails to her, inserting the terse phrase "How would you feel about living in "fill in the city"?" But the truth was that I was often not sure whether becoming a division chief would be a terrific career advancement or a terrible research career-killing move. And there really were not very many places to turn for good advice. I was very active in the SPR, but that organization seemed mostly focused on getting the most junior physician-scientists going at that critical period soon after fellowship. After a considerable amount of time spinning my wheels about that question-and I mean that literally as I undoubtedly did my best thinking when I was out cycling-, I decided to decline opportunities to look at division chief openings. While I think I made the right decision for me in the end, I firmly believe that the process could have been less stressful and probably more robust if I had ready access to others who had preceded me on a comparable path, even if they had decided differently for their own careers. Thankfully, the APS's distinguished members have the experience and the wisdom to assist younger academic pediatricians currently searching for similar career guidance. We have a wonderful opportunity to make ourselves available to those currently on paths that we have already traversed, if only to point out which way not to go.

Now, I wish to focus on the other end of the career trajectory, namely, our most experienced academic pediatricians. Another major demographic factor relevant for Career Support is the increasing longevity of academic careers. Notwithstanding the recent reduced life expectancy in the United States attributable, at least in part, to the opiate epidemic, people in the socioeconomic stratum that includes physicians are living longer than ever. And doctors are working later in life. To provide some startling figures: in the nearly 40 years from 1975 to 2013 , the number of practicing physicians $\geq 65$ years nearly quadrupled, reaching nearly a quarter of a million, and, in 2015 , nearly $25 \%$ of practicing physicians were in that 65 -and-older age group. ${ }^{14}$ [Mid-talk conflict of interest disclosure-l just turned 60 so this topic is of keen personal relevance]. Mark Batshaw, another former APS President, drew our attention to the unmet needs of older academic pediatricians, leading to excellent presentations at last year's PAS meeting and more this year. For the Career Support initiative, we will expand what we are doing to help our more senior members, whether they are transitioning to new roles within academia, often after long runs in leadership, or retiring but choosing to remain engaged with Pediatrics and our Society.

While the Career Support initiative of the APS strategic plan is inwardly focused on Pediatrics and the APS itself, the other two initiatives, Advocacy and Thought Leadership, largely face outwards toward academic medicine more broadly and to all of society. As such, I will address them together, even though they will be distinct efforts.

At the outset of this talk, I alluded to the beginnings of the APS and Jacobi's first presidential address. I want to return to Jacobi's remarks, as I believe his concluding comments resonate for the outward aspects of our agenda. Recall that Abraham Jacobi was an immigrant-to be precise, a German Jewish Communist who had been imprisoned in Germany for treason. ${ }^{15}$ In fact, when he escaped to England, he first stayed with Karl Marx in London and then Frederick Engels in Manchester. Perhaps instructive for our day, he succeeded wildly once admitted to the United States. Throughout his career, Jacobi strove to ameliorate what we would today call the social determinants of health. He understood the importance of proper nutrition for infants, becoming an advocate for breastfeeding, and railed against the conditions in orphanages that were associated with an appalling mortality rate to give two prominent examples. ${ }^{15,16}$ In the concluding section of Jacobi's Presidential Address, he stated that "every physician is by destiny a 'political being' in the sense in which the ancients defined the term, that is, a citizen of a commonwealth, with many rights and great responsibilities. The latter grow with increased power, both physical and intellectual."1 Jacobi averred that the members of the APS through their efforts in child health-related research, pediatric medical education, and interactions with influential members of the public would be, and I quote, "a lasting blessing to the community." 1

Today, we are unquestionably facing issues every bit as serious as those that confronted the founders of the APS. Like them, we have the opportunity to use our privileged positions in understanding children's health to be a blessing to our communities. Let me provide some obvious examples. At the current time, the world is confronting the challenge of climate disruption, an event of such overwhelming and dreadful seriousness that our minds have trouble contemplating the consequences. An estimate from the World Health Organization is that children under the age of 5 years will shoulder $80 \%$ of the burden to human health attributable to climate disruption. ${ }^{17}$ Climate disruption is leading not only to food and water insecurity with direct impact on growing youngsters but also adverse consequences to the mental well being of children from the strife that attends such shortages. For instance, some have argued that the humanitarian disaster, that is, Syria, arose in good measure due to climate disruption. ${ }^{18,19}$ Young children, along with the elderly, are more susceptible to extreme heat. The increased ferocity of weather events, such as hurricanes with greater flooding, also hits young children the hardest. And then there are the effects of toxic stress that all of those ill effects engender. Within our Society's membership, we 
430

have the expertise to speak cogently and persuasively about the need to protect vulnerable children, and we must find every opportunity to engage in discussions of this topic in the public space.

A second example is gun violence. The numbers are too familiar so as to become numbing. In this country, we lose $>3000$ children and adolescents to firearms annually, $60 \%$ to homicides, $35 \%$ to suicides, and the rest to unintentional injuries. ${ }^{20}$ The annual death rate of children and teenagers from firearms in the U.S. has been relatively constant over the past 10 years, which stands in stark contrast to the $40 \%$ decrease in pediatric motor vehicle deaths, attributed to common sense interventions such as increased use of seat belts and child safety seats as well as better engineering of cars and roads. Comparison of the child and adolescent firearm death rates in the U.S. to those of other high-income countries reveals that ours is $>35$ times higher. Despite Congress's obstruction of meaningful research about gun violence, which might inform public policy, there is considerable understanding of the epidemiology of this annual slaughter and its attendant psychosocial costs.

The APS has an important role to play in the public conversation. And we have been using our voice. Last year, the Pediatric Policy Council (PPC), which is the collaborative through which the APS and our three pediatric partner organizations advocate in Washington, worked to advance the gun violence prevention agenda. Specifically, after studying the costs of research, PPC members were able to make a strong case for increasing the ask to Congress from $\$ 10 \mathrm{M}$ to $\$ 50 \mathrm{M}$ in the aftermath of the tragic Parkland High School mass shooting. Our advocacy partners for this issue, including the AAP as well as the Giffords and Brady gun violence prevention organizations, signed onto this upwardly revised appropriations request. While that appropriation did not make it through the 115th Congress last year, there is more support for it in the 116th Congress, reflecting the changes in the House of Representatives post midterm elections. The PPC has also developed a list of gun violence research priorities, strengthening the hands of members of congress who are backing this effort.

While our advocacy has not nearly achieved our goals around gun violence prevention yet-that will likely require additional political leverage gained with future elections-, there are lessons from the important advocacy work to date: the APS must leverage its expertise around issues relevant to children's health, particularly with respect to research; that we must patiently but doggedly pursue change around those issues that we prioritize, and that our partnerships with other like-minded advocacy organizations vastly multiply the impact of our advocacy work.

As we seek to be a blessing to our communities through the APS's Advocacy and Thought Leadership initiatives, we will, I believe, be capturing the essence of what called us to become physicians and then pediatricians years ago. Permit me to share a bit of my own story to illuminate this point. More than 15 years ago, I was given what turned out to be my most important career opportunity. I was visiting another academic institution to give a seminar about my group's discovery of a disease gene, the one underlying a rare heart-hand syndrome that most of us will never see called Char syndrome. During one of my meetings after the talk, a faculty member casually mentioned that their team had some DNAs lying around from a few families with Noonan syndrome and that perhaps I could use them in my research. After later sweet-talking their group's Principal Investigator into letting me take possession of those precious samples, we were in business. A mere 3 months later, thanks to the efforts of my brilliant post-doctoral fellow, Marco Tartaglia, we submitted our first manuscript on Noonan syndrome, describing the discovery of the first gene for that trait, PTPN11. ${ }^{21}$ That cracked open the study of what are now known as the RASopathies. Fast forward to today and the impact of this seemingly random event on my career is apparent-many papers and grants and lots of speaking opportunities. Arguably, I would not be standing here before you this morning were it not for this scientific breakthrough.

But that is all about me and not about being a blessing to a community. The latter came soon after our first Noonan syndrome paper was published. A remarkable woman named Wanda Robinson, the mother of a teenager with the trait, reached out to me. Wanda had founded The Noonan Syndrome Support Group and invited me to their next summer conference. As I headed off to that event, I really did not know what to expect, having never attended any parent-led disease-centered meeting. Soon, I found myself encountering more children with Noonan syndrome than I could have ever imagined. Their parents knew so much but also had so many questions and expressed so much appreciation that the several physicians attending the conference had taken the time to come answer them. An overflowing room was transfixed as I explained the genetic science-how we had made this discovery, how we and others were beginning to unravel the pathogenesis of their children's woes, and what all of that might mean for their children's futures. There were tears in their eyes when I related how we had determined that treatment for the neurocognitive deficits associated with Noonan syndrome might be possible, even as I stressed that it would take years to make that a reality. Their warm embraces, both metaphorical and literal, spoke volumes of their gratitude.

As the years have gone by, I look forward to the biennial Noonan syndrome family conferences more than ever. Plus now, I am honored to serve the same role for the families of another RASopathy, a more severe trait called cardiofaciocutaneous syndrome. And thanks to the power of social media, affected families from around the world reach out to me for advice on their kids and, increasingly, their fetuses. Sometimes, I know the answers, but when I don't, I am fortunate to have access to many others with expertise in the RASopathies to see if any of them has previously encountered the particular issue at hand.

These parents always thank me, and sometimes say they were surprised that I answered their emails or made time to Skype with them. But honestly, I'm the one who leaves each encounter amazed, feeling I have received so much more than I have given. If you could have met the 15-year-old version of Bruce Gelb after he completed a summer as a candystriper at St. Peter's Hospital in New Brunswick, New Jersey and had decided to become a doctor, you undoubtedly would have enjoyed a chuckle, not just because of his big curly hair but because of his exuberant optimism about serving humanity through healing. While that spirit surely needed the tempering of life's experiences, for most of us, and unquestionably for me, it was, over time, tamped down amidst the hubbub of daily living, in both the professional and personal spheres. I am unusually fortunate that a relatively random scientific finding led to the rekindling of that sense of service, providing me with frequent opportunities to serve as a blessing to the RASopathy community.

In the coming years, I hope that the focus of the APS on Advocacy and Thought Leadership will provide similarly meaningful opportunities for all of our members to use their learnedness and expertise as well as to reignite their passion in serving as blessings to myriad communities. Given the crying needs of these tumultuous times, permit me to invoke the third clause of Rabbi Hillel's famous aphorism:

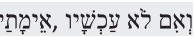

"And if not now, when?"

\section{ADDITIONAL INFORMATION}

Competing interests: I discuss my interactions with the community of families impacted by Noonan syndrome. My institution receives royalties, of which I derive a 
percentage, for genetic testing for this disorder from GeneDx, Preventive Genetics, Correlegan, and LabCorp.

Publisher's note: Springer Nature remains neutral with regard to jurisdictional claims in published maps and institutional affiliations.

\section{REFERENCES}

1. Jacobi, A. in Transactions of the American Pediatric Society (ed. Watson, W. P.) 6-17 (J.B. Lippincott, Philadelphia, PA, 1890).

2. Watson W. P. in Transactions of the American Pediatric Society (ed. Watson, W. P.) 1-5 (J.B. Lippincott, Philadelphia, PA, 1890).

3. Division of Reproductive Health, National Center for Chronic Disease Prevention and Health Promotion, CDC. Achievements in public health, 1900-1999: healthier mothers and babies. MMWR Wkly. 48, 849-858 (1999).

4. In Transactions of the American Pediatric Society (ed. Watson, W. P.) ix-xiii (J.B. Lippincott, Philadelphia, PA, 1890).

5. Gonzales, S. \& Sawyer, B. How does infant mortality in the U.S. compare to other countries? Kaiser Family Foundation (https://www.healthsystemtracker.org/chartcollection/infant-mortality-u-s-compare-countries/\#item-infant-mortality-higheru-s-comparable-countries) (2017).

6. American Pediatric Society: 2019 Five-year Strategic Plan (https://www.aps1888 org/wp-content/uploads/2019/01/05-APS-Executive-Summary.pdf) (2019).

7. Stoll, B. J. American Pediatric Society 2013 presidential address: 125th anniversary of the American Pediatric Society-lessons from the past to guide the future. Pediatr. Res. 74, 466-472 (2013).

8. Stapleton, F. B. American Pediatric Society 2012 Presidential Address: mind the gap. Pediatr. Res. 72, 441-443 (2012).

9. Fuentes-Afflick, E. American Pediatric Society 2018 Presidential Address-the courage of our dreams. Pediatr. Res. 84, 582-585 (2018).
10. Ferriero, D. M. American Pediatric Society 2015 Presidential Address: leaky pipes, glass ceilings, and changing landscapes-time to renovate the pediatric house. Pediatr. Res. 78, 589-593 (2015).

11. Jagsi, R., Motomura, A. R., Griffith, K. A., Rangarajan, S. \& Ubel, P. A. Sex differences in attainment of independent funding by career development awardees. Ann. Intern. Med. 151, 804-811 (2009).

12. Witteman, H. O., Hendricks, M., Straus, S. \& Tannenbaum, C. Are gender gaps due to evaluations of the applicant or the science? A natural experiment at a national funding agency. Lancet 393, 531-540 (2019).

13. Moss-Racusin, C. A., Dovidio, J. F., Brescoll, V. L., Graham, M. J. \& Handelsman, J. Science faculty's subtle gender biases favor male students. Proc. Natl Acad. Sci. USA 109, 16474-16479 (2012).

14. Dellinger, E. P., Pellegrini, C. A. \& Gallagher, T. H. The aging physician and the medical profession: a review. JAMA Surg. 152, 967-971 (2017).

15. Ligon-Borden, B. L. \& Jacobi, A. MD: Father of American Pediatrics and advocate for children's health. Semin. Pediatr. Infect. Dis. 14, (245-249 (2003).

16. Haggerty, R. J. \& Jacobi, A. MD, respectable rebel. Pediatrics 99, 462-466 (1997).

17. Quantitative risk assessment of the effects of climate change on selected causes of death, 2030s and 2050s. World Health Organization (http://www.who.int/iris/ handle/10665/134014) (2014)

18. Kelley, C. P., Mohtadi, S., Cane, M. A., Seager, R. \& Kushnir, Y. Climate change in the Fertile Crescent and implications of the recent Syrian drought. Proc. Nat Acad. Sci. USA 112, 3241-3246 (2015).

19. Gleick, P. H. Water, drought, climate change, and conflict in Syria. Weather Clim. Soc. 6, 331-340 (2014).

20. Cunningham, R. M., Walton, M. A. \& Carter, P. M. The major causes of death in children and adolescents in the United States. N. Engl. J. Med. 379, 2468-2475 (2018).

21. Tartaglia, M. et al. Mutations in PTPN11, encoding the protein tyrosine phosphatase SHP-2, cause Noonan syndrome. Nat. Genet. 29, 465-468 (2001). 